\title{
Urbanisation and incidence of acute lymphocytic leukaemia among United States children aged 0-4
}

\author{
AS Adelman*,I, CC McLaughlin², X-C Wu ${ }^{3}, \mathrm{VW} \mathrm{Chen}^{3}$ and FD Groves ${ }^{4}$ \\ 'Department of Biostatistics, Bioinformatics and Epidemiology, Medical University of South Carolina, 135 Cannon Street, Charleston, SC 29425, USA; \\ ${ }^{2}$ New York State Cancer Registry, Corning Tower, Room 536, Empire State Plaza, Albany, NY 12237, USA; ${ }^{3}$ Epidemiology Program, School of Public \\ Health, Louisiana State University Health Sciences Center, 1600 Canal Street, Suite 800, New Orleans, LA 70 I I2, USA; ${ }^{4}$ Department of Epidemiology \\ and Clinical Investigation Sciences, School of Public Health and Information Sciences, University of Louisville, 555 South Floyd Street, Room \#4053, \\ Louisville, KY 40202, USA
}

Acute lymphocytic leukaemia (ALL) incidence among children under 5 years of age was examined, utilising data from 24 United States cancer registries. County-based incidence rates among white children were compared across four levels of urbanisation: large and small metropolitan counties, and adjacent and nonadjacent rural counties. In metropolitan areas, the incidence of ALL was lower among blacks (rate ratio $(R R)=0.38$, confidence interval $(C l)=0.33-0.44$ ) and among Asians/Pacific Islanders (RR $=0.78$, $\mathrm{Cl}=0.63-0.97)$ than among whites. Among white children, the incidence of ALL decreased across the four strata of urbanisation, from 67 to 62 to 65 to 54 cases per million person-years at-risk (two-sided trend $P=0.009$ ), such that rates were significantly lower in the most remote rural counties than in the most populous metropolitan counties $(R R=0.80,95 \% \mathrm{Cl}=0.70-0.9 \mathrm{I})$. British Journal of Cancer (2005) 92, 2084-2088. doi:I0.1038/sj.bjc.6602607 www.bjcancer.com

Published online 10 May 2005

(c) 2005 Cancer Research UK

Keywords: leukaemia; children; race; urban-rural differences

Acute lymphocytic leukaemia (ALL) is the most common subtype among children. The peak incidence of childhood leukaemia occurs before age 5 ; almost half of all cancers diagnosed at ages 2 and 3 are leukaemias, and about $80 \%$ of all leukaemias occurring before age 10 are ALL. Incidence of childhood ALL in the US is approximately twice as high in whites as in blacks and approximately $20 \%$ higher among boys than girls at age $<5$ years (Smith et al, 1999).

Previous studies of the relationship between childhood ALL and demographic variables such as urban/rural status and population density have yielded inconsistent results. Studies in the UK (Alexander et al, 1990,1996; Gilman and Knox, 1998; Dickinson and Parker, 1999) have generally shown higher rates of ALL or non-Hodgkin's lymphoma (NHL) in rural areas. However, studies in Taiwan (Li et al, 1998), Australia (McWhirter and Bacon, 1980), Greece (Petridou et al, 1997), Sweden (Hjalmars and Gustafsson, 1999), and the United States (Muirhead, 1995) have shown higher incidence of ALL in urban or high-density regions.

The present study is designed to test the hypothesis that incidence of ALL among US children aged 0-4 increases with increasing degree of urbanisation. Acute nonlymphocytic leukaemia (ANLL) and NHL rates were also computed for comparison.

\section{MATERIALS AND METHODS}

County-level incidence data for haematopoietic and lymphoproliferative malignancies among children under 5 years of age during

*Correspondence: AS Adelman; E-mail: adelmaas@musc.edu

Received 5 January 2005; revised 30 March 2005; accepted 4 April 2005; published online 10 May 2005
1995-2000 were obtained from 24 population-based cancer registries (Arizona, Colorado, Connecticut, Atlanta, Idaho, Illinois, Iowa, Kentucky, Louisiana, Michigan, Montana, Nebraska, New Jersey, New Mexico, North Carolina, Oregon, Pennsylvania, Rhode Island, South Carolina, Utah, Washington, West Virginia, Wisconsin, and Wyoming) participating in the National Cancer Institute's Surveillance, Epidemiology, and End Results (SEER) Program or the Centers for Disease Control and Prevention's National Program of Cancer Registries (NPCR). All registries are members of the North American Association of Central Cancer Registries (NAACCR). The registries included in this study are those which consistently meet high standards for quality (including high data completeness, high internal consistency, low case duplication, low fraction of cases where all information comes from death certificates, and low fraction of missing information on race, gender, and age). Each participating registry specifically consented to provide data for this study. These registries covered about $38 \%$ of the US population under 5 years of age in 2000 . The cancer cases were classified as ALL, ANLL or NHL according to the SEER-modified International Classification of Childhood Cancer (NCI, 2004), as supplied by the SEER ${ }^{\star}$ Stat software (Surveillance Research Program, 2002). For the purposes of this study, NHL was defined as any lymphoma not explicitly classified as Hodgkin's lymphoma.

Age-specific incidence rates were computed for children aged $0-4$ years, stratified by gender, race, and degree of urbanisation. Race was categorised as 'white', 'black', 'Asian/Pacific Islander' (API), and 'American Indian/Alaska Native' (AIAN). Information on specific races in the registries' data was derived from medical records, coded according to standard codes (Hultstrom, 2002), and then grouped into standard race categories in accordance with federal agency standards for the years that the study data were 
collected (Office of Management and Budget, 1994). The API category includes Chinese, Japanese, Filipino, Hawaiian, Korean, Asian Indian-Pakistani, Vietnamese, Laotian, Hmong, Kampuchean, Thai, Micronesian-NOS, Chamorran, Guamanian-NOS (not otherwise specified), Polynesian-NOS, Tahitian, Samoan, Tongan, Melanesian-NOS, Fiji Islander, New Guinean, Other Asian, Pacific Islander-NOS, and Oriental-NOS. All API subcategories were combined into one group because population data for the individual subgroups were not available.

Degree of urbanisation was originally categorised according to the 10 levels $(0-9)$ of the 'rural-urban continuum code' developed by the United States Department of Agriculture (Beale, 2003a). Counties were first designated as 'metropolitan' or 'nonmetropolitan'. Metropolitan counties were further stratified by population size (greater than or less than 1000000 people). The nonmetropolitan counties were divided into subgroups based on adjacency to metropolitan areas as well as percentage of population residing in urban areas. None of the previous studies referenced in this paper (McWhirter and Bacon, 1980; Alexander et al, 1990,1996; Petridou et al, 1997; Gilman and Knox, 1998; Li et al, 1998; Dickinson and Parker, 1999) dealt with the size of populations, but rather with urban/ rural status and distance from urban areas. Therefore, for comparability to previously published studies and to obtain reasonably precise point estimates of incidence rates, we have opted to emphasise the proximity of nonmetropolitan counties to metropolitan areas while collapsing the subcategories of urban population among the nonmetropolitan counties. Counties in this study were grouped into four strata in order of decreasing urbanisation as shown in Table 1. Although individual counties may contain both urban and rural populations, strata 1 and 2 comprise metropolitan counties that are predominantly urban, while strata 3 and 4 comprise nonmetropolitan counties that are predominantly rural.

Cells with fewer than 20 cases are not displayed in order to protect the privacy of the cases, and because when the numbers of cases used to compute incidence rates are small, the reliability of the rates tends to be poor (Brillinger, 1986). Rural-urban gradients over all four strata were assessed using the CochranArmitage test for trend (Agresti, 1990). Pairwise rate ratios (RRs) and their confidence intervals (CIs) (for comparing incidence rates by gender, race, and metropolitan/nonmetropolitan status) were calculated using the maximum likelihood estimate (Rothman and Greenland, 1998).

Population attributable fractions due to urbanisation were calculated, taking into account that 'exposure' to urbanicity is polytomous and basing the structure of the population attributable fraction on the distribution of exposure in cases (Hanley, 2001).

\section{RESULTS}

A total of 2423 cases of ALL were observed in 42306667 personyears at risk in the 24 participating registries. Of the ALL cases, 1921 resided in metropolitan counties and 502 in nonmetropolitan counties. There were a total of 429 cases of ANLL and 144 cases of NHL. Racial characteristics of cases are shown in Table 2.

Incidence rates for ALL, ANLL, and NHL among whites, blacks, and APIs subjects, who resided in metropolitan counties, are shown in Table 3 (data for AIANs are too sparse to be displayed). Black subjects had lower incidence of ALL ( $R R=0.38,95 \%$ $\mathrm{CI}=0.33-0.44)$, ANLL $(\mathrm{RR}=0.74,95 \% \mathrm{CI}=0.57-0.95)$, and NHL $(\mathrm{RR}=0.56,95 \% \mathrm{CI}=0.40-0.80)$ than white subjects, and APIs likewise had lower incidence of ALL than whites $(R R=0.78,95 \%$ $\mathrm{CI}=0.63-0.97)$. Regardless of race, boys had a higher incidence of ALL $(\mathrm{RR}=1.17,95 \% \mathrm{CI}=1.09-1.25$, data not shown) and NHL $(\mathrm{RR}=1.99,95 \% \mathrm{CI}=1.57-2.52$, data not shown) than girls, while ANLL rates did not vary by gender $(\mathrm{RR}=1.09,95 \% \mathrm{CI}=0.93-$ 1.29 , data not shown).

Due to sparse data for non-whites, the rural-urban gradients were assessed using only the data for whites (Table 4). There were no rural-urban gradients in incidence of ANLL or NHL among whites of either gender. Among whites of both genders, the incidence of ALL decreased across the four strata of urbanisation, from 67-62 to 65-54 cases per million person-years at-risk (twosided trend $P=0.009$ ), such that rates were significantly lower in the most remote rural counties than in the most populous metropolitan counties $(\mathrm{RR}=0.80,95 \% \mathrm{CI}=0.70-0.91)$. The rural-urban gradient was even stronger among boys $(R R=0.71$, $95 \% \mathrm{CI}=0.59-0.85$, two-sided trend $P=0.008$ ), but was not statistically significant among girls $(\mathrm{RR}=0.92,95 \% \mathrm{CI}=0.76-$ 1.10 , two-sided trend $P=0.31$ ), such that the overall rural-urban gradient for children of both genders was driven by the gradient among boys (data not shown).

The proportion of childhood ALL cases attributable to any degree of urbanisation beyond 'rural, nonadjacent' was 16\% (24\% for boys $v s 5 \%$ for girls, data not shown).

\section{DISCUSSION}

We found that incidence of ALL among white children was higher in urban areas than rural areas. Among white boys aged $0-4$ years in rural areas, it was $29 \%$ lower than among their urban counterparts; however, no such rural-urban gradient was detected among white girls.

Previous studies in Australia, Greece, Taiwan, Sweden, and the United States also found increased rates of childhood ALL in urban areas. Acute lymphocytic leukaemia incidence among children living in Brisbane City, Australia, during 1973-1979 was

Table I Classification of counties by degree of urbanisation

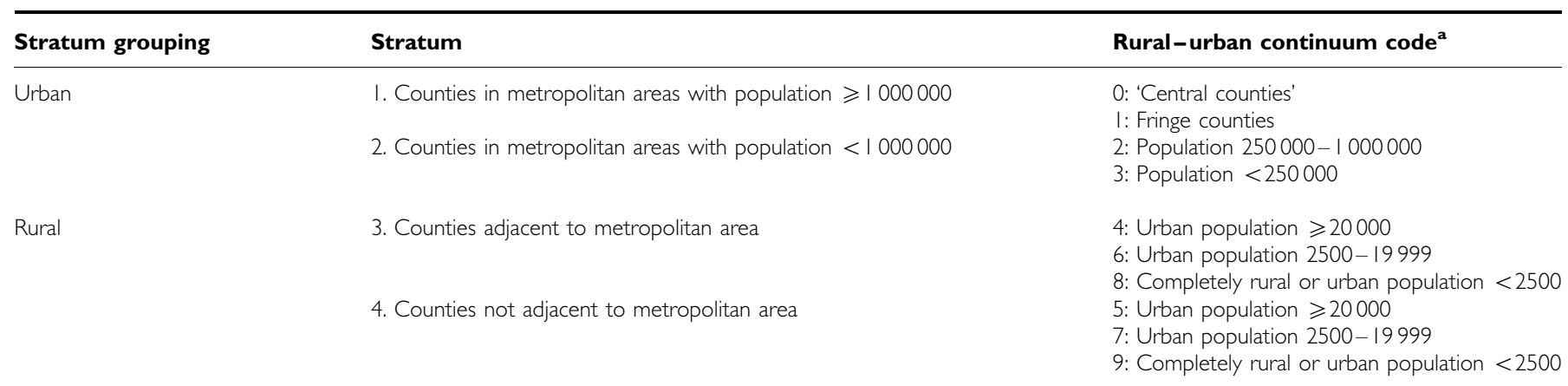

aeale C (2003). Description of the rural-urban continuum codes prior to 2003. USDA Economic Research Service: http://www.ers.usda.gov/Briefing/Rurality/RuralurbCon/ priordescription.htm. 
Table 2 Racial characteristics of cases

\begin{tabular}{|c|c|c|c|c|c|}
\hline & Whites (\%) & Blacks (\%) & APIs (\%) & AIANs (\%) & Unknown race (\%) \\
\hline ALL, metro (192I cases) & 88 & 8 & 3 & 1 & I \\
\hline NHL, all counties ( 144 cases) & 84 & 10 & 6 & 0 & 0 \\
\hline
\end{tabular}

Note: Percentages are given due to privacy concerns associated with small, exact numbers in some categories. For purposes of this study, ALL (acute lymphocytic leukaemia) is defined as International Classification of Diseases for Oncology, 2nd edn (ICD-O-2) morphology codes 982I and 9828; ANLL (acute nonlymphocytic leukaemia) is defined as codes 9840, 984I, 986I, 9864, 9866, 9867, 987I -9874, 989I, 9894, and 99 10; and NHL (non-Hodgkin's lymphoma) is defined as codes 9590, 959I-9595, 9670-9688, 9690-97।7, 9720, 9723, and 973I-9764. API = Asian/Pacific Islander, AIAN=American Indian/Alaska Native.

Table 3 Paediatric (ages 0-4) cancer incidence rates (per 1000 000) for both genders combined by race and RRs contrasting incidence rates by race in metropolitan counties of 23 US states and Atlanta, 1995-2000

\begin{tabular}{|c|c|c|c|c|c|c|c|c|c|c|}
\hline \multirow[b]{2}{*}{ Race } & \multirow{2}{*}{$\begin{array}{l}\text { Person- } \\
\text { years at } \\
\text { risk }\end{array}$} & \multicolumn{3}{|c|}{ ALL } & \multicolumn{3}{|c|}{ ANLL } & \multicolumn{3}{|c|}{ NHL } \\
\hline & & $\begin{array}{l}\text { No. of } \\
\text { cases }\end{array}$ & $\begin{array}{c}\text { Rate } \\
(95 \% \mathrm{Cl})\end{array}$ & $\operatorname{RR}(95 \% \mathrm{Cl})$ & $\begin{array}{l}\text { No. of } \\
\text { cases }\end{array}$ & $\begin{array}{c}\text { Rate } \\
(95 \% \mathrm{Cl})\end{array}$ & $\operatorname{RR}(95 \% \mathrm{CI})$ & $\begin{array}{l}\text { No. of } \\
\text { cases }\end{array}$ & $\begin{array}{c}\text { Rate } \\
(95 \% \text { Cl) }\end{array}$ & $\operatorname{RR}(95 \% \mathrm{Cl})$ \\
\hline Black & 5985970 & 149 & $25(21-29)$ & $0.38(0.33-0.44)$ & 47 & $8(6-10)$ & $0.74(0.57-0.95)$ & 25 & $4(3-6)$ & $0.56(0.40-0.80)$ \\
\hline API & 1167614 & 59 & $50(38-65)$ & $0.78(0.63-0.97)$ & $<20$ & a & a & $<20$ & a & a \\
\hline White & $2594 \mid 007$ & 1685 & $65(62-68)$ & I.00 (Referent) & 277 & $11(10-12)$ & I.00 (Referent) & 192 & $7(6-8)$ & I.00 (Referent) \\
\hline
\end{tabular}

Source: North American Association of Central Cancer Registries. ${ }^{a}$ Not shown due to sparse data $(N<20)$. RR $=$ rate ratio, $A L L=a c u t e ~ l y m p h o c y t i c ~ l e u k a e m i a, ~ A N L L=$ acute nonlymphocytic leukaemia, NHL = non-Hodgkin's lymphoma, API = Asian/Pacific Islander, AIAN= American Indian/Alaska Native

Table 4 Paediatric (ages 0-4) cancer incidence rates (per I 000000 ) for both genders combined by degree of urbanisation and gender and RRs contrasting incidence rates by degree of urbanisation in 23 US states and Atlanta among whites, 1995-2000

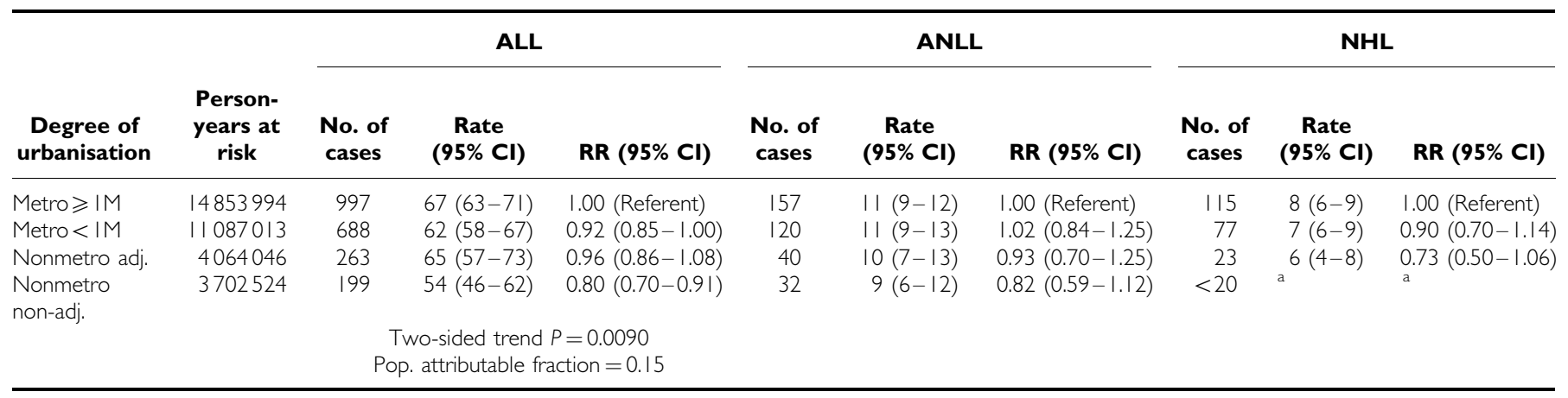

Source: North American Association of Central Cancer Registries. $\mathrm{RR}=$ rate ratio, $\mathrm{ALL}=$ acute lymphocytic leukaemia, $\mathrm{ANLL}=$ acute nonlymphocytic leukaemia, $\mathrm{NHL}=$ nonHodgkin's lymphoma. aNot shown due to sparse data $(N<20)$.

significantly higher than among children living in the (more rural) remainder of the Brisbane Statistical Division $(\mathrm{RR}=1.59$ for children 0-4 years old) (McWhirter and Bacon, 1980). In Greece during 1980-1989, childhood ALL incidence was higher in urban areas than in semiurban or rural areas (Petridou et al, 1997). Similarly, leukaemia incidence rates among children aged 0-4 residing in the 361 districts of Taiwan increased monotonically across four levels of urbanisation, with RRs of 1.0, 1.2, 1.3, and 1.5 in 'rural areas', 'towns', 'cities', and 'metropolitan areas' (trend $P<0.01$ ) during 1981-1990 (Li et al, 1998). The RRs for whites between the extremes in urban status in our study (1.2 for both ALL and ANLL) were comparable to those reported by $\mathrm{Li}$.

Some researchers have assessed the effect of population density, as well as urbanisation per se, on incidence of ALL. Incidence of ALL among Swedish children under age 15 during 1973-1994 (Hjalmars and Gustafsson, 1999) was significantly higher in 'population centres' than in the Swedish countryside (3.99 vs 2.38 cases per $100000 ; \mathrm{OR}=1.68 ; 95 \% \mathrm{CI}=1.44-1.95)$; no significant rural-urban gradient was observed for ANLL (0.67 vs 0.59 cases per $100000 ; \mathrm{OR}=1.13 ; 95 \% \mathrm{CI}=0.98-1.32)$. The childhood ALL incidence rates in Sweden increased monotonically with increasing degrees of urbanisation (3.32, 3.41, and 3.65 cases per 100000 in 'rural', 'semiurban', and 'urban' areas, respectively), and also with increasing population density $(3.55,3.63$, and 4.09 cases per 100000 in areas with $<400,400-800$, and $>800$ persons per square kilometer, respectively). Likewise, white children under 15 years of age during 1978-1982 in high-density census tracts in three US metropolitan areas (San Francisco-Oakland, Detroit, and Atlanta) had higher combined incidence rates of leukaemia and NHL $(R R=1.4)$ than those in low-density census tracts. Borderline elevations in incidence of leukaemia and NHL were detected among whites in medium-density areas $(\mathrm{RR}=1.3)$ and among all races in medium-density $(R R=1.2)$ and high-density $(R R=1.3)$ 
areas (Muirhead, 1995). Since Muirhead dealt with population density only within urban areas, his RRs are not directly comparable to ours. Our study builds upon Muirhead's analysis by incorporating more recent data (1995-2000 instead of 19781982) from many more cancer registries and by directly comparing ALL incidence in urban $v s$ rural counties instead of just in urban counties.

In contrast with previously published findings in Taiwan (Li et al, 1998), Australia (McWhirter and Bacon, 1980), Greece (Petridou et al, 1997), Sweden (Hjalmars and Gustafsson, 1999), and the United States (Muirhead, 1995), studies in the United Kingdom found higher incidence of childhood ALL in rural areas. The incidence of ALL among children aged 1-7 years in 3270 electoral wards in England and Wales during 1984-1988 increased over four levels of distance from built-up areas $(\mathrm{RR}=2.2$; trend $P=0.002$ ) for wards $>20 \mathrm{~km}$ from a built-up area (Alexander $e t a l$, $1990,1996)$. Likewise, in a multivariate study of cancer among a cohort of children aged 1-14 born in the rural English district of Cumbria during 1969-1989, those who did not reside in a built-up area had an RR for ALL/NHL of 2.0 compared with those who resided in a built-up area (Dickinson and Parker, 1999). Paediatric (ages $0-15$ ) leukaemia and lymphoma mortality (adjusted for birth density, birth year, and radon exposure) in inner London during 1953-1980 was significantly lower than in less-urban areas in the UK $(\mathrm{RR}=0.80)$ (Gilman and Knox, 1998). However, the differences in mortality may have reflected higher survival rates in London than in outlying areas.

Our finding of a rural - urban gradient in ALL incidence among boys but not girls, while unexpected, was not unprecedented. There was a male predominance of ALL among Greek children in urban areas (65.9 per million boys $v s 56.5$ per million girls) and semiurban areas (45.3 per million boys $v s 42.5$ per million girls), although the opposite was true in rural areas (42.2 per million boys vs 46.4 per million girls) (Petridou et al, 1997). Furthermore, there was greater geographic variation in ALL incidence among white boys than among white girls, as reported by 12 US cancer registries during 1973-1986 (Linet and Devesa, 1991).

It must also be noted in our study that just as there is no ruralurban gradient in ALL incidence among girls, there is likewise no gender disparity in ALL incidence in the most rural areas. Thus, one could argue that exposure to some unknown urban-associated risk factor occurs more commonly among boys than among girls. Alternatively, white boys in urban areas could be more susceptible to an unknown risk factor.

This is an ecologic study; it does not deal with individual subjects or individual-level traits or exposures, but rather with the characteristics of large groups of counties. As such, it is possible that positive results among white boys may be due to genetic or environmental risk factors associated with urban residence in the United States that were not assessed in this study. It is also impossible to determine from our data whether or not cases developed cancer in the same counties where they were diagnosed; conceivably, children with preclinical cancer could be more likely to move from rural to urban areas than vice versa.

It is also conceivable that the considerable difference in county size east and west of the Rocky Mountains could affect ecologic measures (e.g. small counties would be expected to be more homogeneous than large counties), but since we have lumped Beale's 10 continuum codes into a mere four so that population is only a distinguishing factor between the two metropolitan strata, urban/rural composition of large counties probably does not affect this potential problem. That large nonmetropolitan counties, with their bigger perimeters, may be more likely to be adjacent to metropolitan areas than small counties might be more of a concern; however, according to the map of the 1993 version of the codes (Beale, 2003b), there are numerous rural nonadjacent counties in the areas around and on both sides of the Rocky Mountains, so this does not seem to be an actual problem.

Our findings do not conclusively prove that there is an association between urbanisation and childhood ALL, nor have we proven that any risk factor for childhood ALL occurs more commonly in urban areas. Rather, our results indicate that further research into the nature and causes of the rural-urban gradient in childhood ALL is warranted.

\section{ACKNOWLEDGEMENTS}

This is the work of the Comparative Analysis of Incidence Rates (CAIR) Subcommittee of the Data Evaluation and Publication Committee (DEPC) of the North American Association of Central Cancer Registries (NAACCR). We would like to thank Elizabeth Hamilton-Byrd (Indiana State Department of Health), Howard J Martin (Virginia Cancer Registry, Virginia Department of Health, Richmond), and Lisa Roché (New Jersey State Cancer Registry, New Jersey Department of Health and Senior Services) for their commentary and criticism in the process of writing this paper. This publication is unfunded, and its contents are the responsibility of the authors and do not necessarily reflect the official views of the CDC.

\section{REFERENCES}

Agresti A (1990) Categorical Data Analysis Wiley Series in Probability and Mathematical Statistics. Applied Probability and Statistics. New York: John Wiley \& Sons

Alexander FE, Leon DA, Cartwright RA (1996) Isolation, car ownership, and small area variation in incidence of acute lymphoblastic leukemia in children. Paediatr Perinatal Epidemiol 10: $411-417$

Alexander FE, Ricketts TJ, McKinney PA, Cartwright RA (1990) Community lifestyle characteristics and risk of acute lymphoblastic leukaemia in children. Lancet 336: 1461 - 1465

Beale C (2003a) Description of the rural-urban continuum codes prior to 2003. USDA Economic Research Service http://www.ers.usda.gov/Briefing/Rurality/RuralurbCon/priordescription.htm.

Beale C (2003b) ERS/USDA briefing room - measuring rurality: ruralurban continuum codes: rural-urban continuum codes, 1993. USDA Economic Research Service http://www.ers.usda.gov/Briefing/Rurality/ RuralUrbCon/code93.htm.
Brillinger DR (1986) The natural variability of vital rates and associated statistics (with discussion). Biometrics 42: 693-734

Dickinson HO, Parker L (1999) Quantifying the effect of population mixing on childhood leukaemia risk: the Seascale cluster. Br J Cancer 81: $144-151$

Gilman EA, Knox EG (1998) Geographical distribution of birth places of children with cancer in the UK. Br J Cancer 77: 842-849

Hanley JA (2001) A heuristic approach to the formulas for population attributable fraction. I Epidemiol Community Health 55: $508-514$

Hjalmars U, Gustafsson G (1999) Higher risk for acute childhood lymphoblastic leukaemia in Swedish population centres 1973-94. Swedish Child Leukaemia Group. Br J Cancer 79: 30-33

Hultstrom D (2002) Data Standards and Data Dictionary, Version 10: 7th edn. Springfield, IL: North American Association of Central Cancer Registries 
Urbanisation and incidence of acute lymphocytic leukaemia

AS Adelman et al

Li CY, Lin RS, Lin CH (1998) Urbanization and childhood leukaemia in Taiwan. Int J Epidemiol 27: 587-591

Linet MS, Devesa SS (1991) Descriptive epidemiology of childhood leukaemia. Br J Cancer 63: 424-429

McWhirter WR, Bacon JE (1980) Epidemiology of acute lymphoblastic leukaemia of childhood in Brisbane. Med J Aust 2: 154-155

Muirhead CR (1995) Childhood leukemia in metropolitan regions in the United States: a possible relation to population density? Cancer Causes Control 6: 383-388

NCI (2004) SEER Modification of the ICCC National Cancer Institute http:// seer.cancer.gov/iccc/seericcc.html.

Office of Management and Budget (1994) Standards for the classification of federal data on race and ethnicity: In Federal Register
Petridou E, Alexander FE, Trichopoulos D, Revinthi K, Dessypris N, Wray N, Haidas S, Koliouskas D, Kosmidis H, Piperopoulou F, Tzortzatou F (1997) Aggregation of childhood leukemia in geographic areas of Greece. Cancer Causes Control 8: 239-245

Rothman KJ, Greenland S (1998) Modern epidemiology. Philadelphia, PA: Lippincott-Raven, pp 237-239

Smith MA, Ries LAG, Gurney JG, Ross JA (1999) Leukemia. In Cancer Incidence and Survival Among Children and Adolescents in the United States SEER Program, 1975-1995, National Cancer Institute, SEER Program, NIH Pub. No. 99-4649 Ries LAG, Smith MA, Gurney JG, Linet M, Tamra T, Young JL, Bunin GR (eds) pp 17-34. Bethesda: NIH

Surveillance Research Program (2002) SEER ${ }^{\star S t a t}$. National Cancer Institute 